\title{
The Influences of Demographic Characteristics on Tourism Decision: Taking Daming Lake in Ji'nan as an Example
}

\author{
Qiang Zhao, Xiu-mei Li, Run-dong Wang and Yong-quan Su \\ School of Resources and Environment University of Jinan, Shandong Province, China \\ stu_zhaoq@ujn.edu.cn
}

\begin{abstract}
Demographic characteristics and tourists' decisions were studied basing on field survey and questionnaires in Daming Lake scenic spot and the impact of demographic characteristics on tourists' decisions were analyzed using Crosstab analysis. Demographic characteristics indicated that:1) most of tourist's age were between 26 and 46;2)the tourists' percentage increased with the education; 3) most tourist's vocation were public servants and staff in institutions, and an important part were students and the The selfemployed, the freelancers; 4) monthly income concentrated on the right down the middle. The tourists' decisions showed that: 1) most tourists coming from Jin'nan were to relax and those from the other areas were to sightsee; 2) word-of-mouth recommendation and the network was the important way for tourists to obtain the informations of scenic spot; 3 ) most tourists visit Daming Lake with his family or friends. The Crosstab analysis between demographic characteristics and tourism decisions suggested that the age and vocation had some influence on the tourists' purpose and the age also had some influence on the way of obtaining the scenic spot' information.
\end{abstract}

Index Terms - Tourism Decision, Daming Lake Scenic Spot, Tourist Market, Crosstab Analysis

\section{Introduction}

Tourism decision was a special consumption decision, of which the most basic affecting factors included the outside environment which tourists had stayed in and the tourists' internal elements[1]. Fudong Qiu and Ming Wu divided the affecting factors of tourism decisions into tourism service, social support, group support, individual psychology, individual socioeconomic and other factors and they also found that demographic characteristics also limited the tourism decision[2]. Junli Qin and Lan Lin found that gender existed differences in the tourism decision[3]. Hong Luo and some others found that it was affected by tourists' education, income and other objective factors[4]. Fudong Qiu and Jin Wang divided the travel decisionmaking process into seven stages[5], including generating travel ideas, learning about the information on the destination, determining the destination or tourist routes, determining the time, cost and the travel way, determing whether to go on a journey and carrying out the tourism planning. Basing on a sample, it was analyzed that the demographic characteristics of the tourists in Daming Lake scenic spot, the tourism decision in the first, second, third and fifth stage and after tourism, and the influence of demographic characteristics on tourism decision-making.

\section{Research Methods}

A. Site Description

Daming Lake scenic spot is located in the centre of Ji'nan $\left(36^{\circ} 40^{\prime} \mathrm{N}, 117^{\circ} 01^{\prime} \mathrm{E}\right)$ which is a warm temperate continental monsoon climate. Daming Lake is known as Spring City Pearl, which is one of the three major scenic spots in Ji'nan. The water in Daming Lake come from Baotu Spring, Pear Spring, Five Dragon Pool and Black Tiger Spring. The water area is $0.46 \mathrm{~km}^{2}$ and the mean depth is about $2 \mathrm{~m}$. Lotus are planted in the water and Willows are planted around the water, so Daming Lake has become a portrayal of typical Spring City. Many buildings surround the lake and Underwater World was constructed in 2013.In the scenic spot some custom activities were organized regularly and traditional food can be found in the restaurents.

\section{B. Questionnaires}

The questionnaires included the social attributes of the tourists (gender, age, marital status, education level, occupation and monthly income) and the tourism purpose, the way, the way of information acquisition, the factors to consider to select the tourism destination, the behavior after the tourism. Sampling survey was carried out in the weekends from March to May, and the "golden week" holidays (From May 1 to May 3), 2014. The tourists in the scenic spot were required to write in the questionnaires. Altogether 404 questionnaires were gived out, and 381 valid questionnaires were recovered and the avaliable percentage was $94.31 \%$.

\section{The Influences of Demographic Characteristics on Tourism Decision}

\section{A. Demographic Characteristics}

The percentage of the men and women was respectively $58.3 \%$ and $41.7 \%$, which was consistent of sexual composition in china. The ratio of male : female in the tourists was slightly higher than national that, which was because the effect of traditional culture, the gender role, and society's status, occupation and income[6]. Figure 1 showed the age of most tourists were between 26 and 45, the next were 16-25 and 46-60 years old tousists accounted for an important part. The tourists coming from outside Ji'nan whose age was under 16 years old and over 60 years old were rare. The visitors under 16 years old coming from Ji'nan were few, but those over 60 was an important part, even more than those whose age was between 46 and 60 , which might be 
because the elder were free and keen to the leisure, and also because of preferential policies to the elder in the scenic spot.

The crosstab between the age and marital status showed that the main source were those including the single whose age was between 17 and 25 and the married whose age was between 26 and 45 .

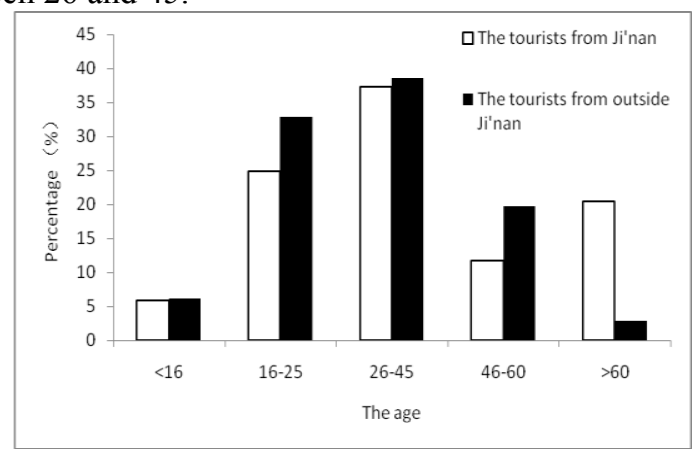

Fig.1 Age composition of tourists

The education affected the perceptions about tourism, and then the decision-making of tourism. In general, the higher the degree was, the greater the tourism demand was[7]. The visitors in Daming Lake who received higher education were the most (68.24\%). The next were those whose received high school, technical secondary school education (26.51\%). The percentage of the turists whose received junior middle school and less education was only $5.25 \%$.

Public servants and staff in institution in visitors were the most $(44.88 \%)$, students second $(23.10 \%)$ and the selfemployed and freelancers $(22.31 \%)$ were approximately equalling to the sum of students. retirees, accounting for $7.87 \%$, were the fewest and the rest was $1.84 \%$. Public servants and staff in institution have a good economic foundation and relatively regular holidays, thus those were the most important tourists. As the students had more leisure time, less social pressure, curiosity about the outside and economical support from family, they were an important part in tourists. The self-employed and freelancers had a strong income, but as it was alternative that the time spented on tourism and obtaining economic income, it was difficulty to increase the amount of those tourists.

The correlation was positive between the economic strength and the travel ability[8]. The tourists in Daming Lake whose monthly income were between 3000 and 6000 yuan accounted for $39.11 \%$ and the tourists who had no economical income, mainly students and the elderly, accounted for $22.57 \%$ and those whose income are less than 3000 yuan or higher than 10000 yuan were both few.

\section{B. Tourism Decision}

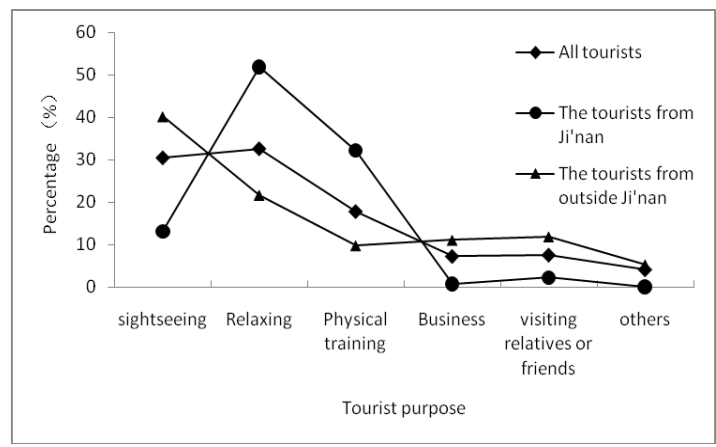

Fig. 2 The percentage of tourist purpose

1) Tourist purpose: Figure 2 showed that tourist purpose of most tourists were relaxing and sightseeing. The pencentage of physical training was middle and while visiting relatives and friends, business and other purpose were less. There was diffrent in tourist purpose for the tourists who come from Ji'nan and from outside Ji'nan. The purpose of most Ji'nan's tourists was to relax and had a physical training, however, most visitors outside Ji'nan was to sightsee. Compared with those from Ji'nan, the visitors outside Ji'nan who were to relax and have a physical training declined sharply, while who were on business and to visit relatives and friends increased.

2) The way of tourism information acquisition: Excluding local residents in the visitors, most visitors got the information on travel through word-of-mouth recommendation $(28.35 \%)$. Some visitors got the information through Internet (19.69\%). To got the information the ways through television, radio and alike mass medias, a travel agency or other were less, respectively accounting for $7.35 \%, 5.25 \%$ and $1.91 \%$.

3) The considered factors to select the destination: The most considered factor was the quality of the tourism resources $(18.95 \%)$, the second was the number of tourists in scenic spots $(14.74 \%)$. The infrastructure in scenic spots $(13.04 \%)$, the traffic convenience $(12.57 \%)$, the popularity $(12.30 \%)$, and the traffic cost $(11.28 \%)$ were also important factors. The ticket price of scenic spots $(9.10 \%)$ and the consumption inside the scenic spots $(8.02 \%)$ became less important considering factors, which might be associated with the income increase.

4) Travel way: Most tourists visited Daming Lake with his family (37.53\%) and the second was with his friends $(26.51 \%)$. The tourists who visited the scenic spot with travel agency accounted for $16.27 \%$ and they all come from outside Ji'nan. However, the tourists whose tourism information come from travel agencies accounted for no more than $1 / 3$ of the tourists traveling with group, which showed that many tourists did not blindly follow the tourism information issued by the travel agencies and searched for the information by other ways. The tourists who were organized by their corporation were rare $(3.15 \%)$.

5) Behavior after tourism: $37.3 \%$ of the visitors would share their tour experiences and feelings with friends or relatives after traveling and $23.6 \%$ would consider whether to come again according to this travel conditions and $17.3 \%$ 
would go online to evaluate the scenic spots. the rest $21.8 \%$ would be no action.

\section{The Crosstab Analysis between Demographic \\ Characteristics and Tourism Decision-Making}

1) The crosstab analysis between demographic characteristics and tourist purpose: Chi-square test and correlated analysis showed that the age and occupation had some impact on tourist purpose. The Crosstab analysis indicated that there were some differences in tourist purpose to different ages and occupations, the result was shown in Tab.1 Tab.2. Tourist purpose of the tourists below 25 years old were mostly for sightseeing or relaxing. Those whose age was between 26 and 45 were the main group whose purpose were on business. Those above 26 years old increased because of

TABLE 1 Crosstab analysis between tourist purpose and the age

\begin{tabular}{|c|c|c|c|c|c|c|c|}
\hline Age & Business & Sightseeing & Others & Physical training & Visiting relatives or friends & Relaxing & Sum \\
\hline$\leq 25$ & 1 & 54 & 6 & 21 & 7 & 11 & 48 \\
\hline $26-45$ & 19 & 39 & 5 & 22 & 10 & 49 & 145 \\
\hline$\geq 46$ & 9 & 23 & 5 & 25 & 68 & 28 & 99 \\
\hline Sum & 29 & 116 & 16 & 68 & 124 & 381 \\
\hline
\end{tabular}

TABLE 2 Crosstab analysis between tourist purpose and the career

\begin{tabular}{|c|c|c|c|c|c|c|c|}
\hline vocation & Business & Sightseeing & Others & Physical training & Visiting relatives or friends & Relaxing & Sum \\
\hline The The self-employed, retirees and others & 2 & 26 & 3 & 18 & 4 & 20 & 73 \\
\hline Public servants, teachers and technicians & 7 & 15 & 4 & 13 & 13 & 36 & 88 \\
\hline Students and the freelancers & 3 & 54 & 5 & 29 & 4 & 4 & 39 \\
\hline Staff in institution & 17 & 21 & 4 & 8 & 29 & 83 \\
\hline Sum & 29 & 116 & 16 & 68 & 381 \\
\hline
\end{tabular}

TABLE 3 Crosstab analysis between the ways of getting information and the age

\begin{tabular}{|c|c|c|c|c|c|c|c|}
\hline Age & Local residents & Media & Travel company & Others & Recommendation & Network & Sum \\
\hline$\leq 25$ & 50 & 21 & 8 & 0 & 33 & 25 & 137 \\
\hline $26-45$ & 52 & 2 & 7 & 2 & 31 & 31 & 145 \\
\hline$\geq 46$ & 43 & 5 & 5 & 3 & 24 & 19 & 99 \\
\hline Sum & 145 & 28 & 20 & 5 & 108 & 75 & 381 \\
\hline
\end{tabular}

visiting friends and relatives. In addition, along with the longer age, more pepole gone on a trip to have a physical training and less to the others purpose. Crosstab analysis between tourist purpose and occupation indicated that public servants, teachers, and professional and technicians were to relax, while freelancers and students were to sightsee and Staff in institution were the main group traveling for business.

2) The crosstab analysis of demographic characteristics and tourism information acquisition way: Chi-square test and correlated analysis showed that the age and occupation had some impact on tourist purpose. The Crosstab analysis indicated that there were some differences in tourist purpose to different ages and occupations, the result was shown in Tab.1 Tab.2. Tourist purpose of the tourists below 25 years old were mostly for sightseeing or relaxing. Those whose age was between 26 and 45 were the main group whose purpose were on business. Those above 26 years old increased because of visiting friends and relatives. In addition, along with the longer age, more pepole gone on a trip to have a physical training and less to the others purpose. Crosstab analysis between tourist purpose and occupation indicated that public servants, teachers, and professional and technicians were to relax, while freelancers and students were to sightsee and Staff in institution were the main group traveling for business.

\section{Conclusion}

After the expansion projects of Daming Lake in 2009 the infrastructures, the natural and artificial landscape has had obvious improvement[9]. But Daming Lake is situated in old city of Ji'nan which have a dense population, so every day high concentration sewage was discharged into the lake. In addition, some tourists threw garbage in the scenic spot, especially in the peak season. Those maked the environment of Daming lake worse. The present research showed that quality of tourism resources, the tourist number and infrastructure in scenic spots were all important factors when people selected a destination. After the tourism more than $1 / 3$ tourists would tell the other persons their travel experience and more than $1 / 5$ visitors would decide whether to revisit the scenic spot according to the experience, and word-of-mouth recommendation was the main way visitors access to tourism information, so the satisfaction was important to maintain the 
current tourists and develop more tourists. In order to protect tourism resources of Daming Lake, the protective development should be the principle. Those were important to protect the water and environment and control the number who entered to scenic spot during peak season and manage the behaviour of tourists.

It was found that the tourists who were between 26 and 45 were dominating source of Daming Lake scenic spot and the network was an important approach to get information to those tourists. However the visitors in Daming Lake who obtained information through the network were less than $20 \%$. Therefore, managers need to strengthen the content and intensity of network marketing. Visitors accessing to travel information through mass medias accouted for a small part, and their age were under 25. As the family travel is an important way to travel and the child became the center of family tourism decision with the miniaturization of family in the society[10-11], mass medias should be strengthened to expand the tourist market.

\section{Acknowledgment}

The research work was supported by Natural Science Foundation of China under Grant No. 41471160 and Natural Science Foundation of Shandong Provincial under Grant No. ZR2013DL001 and Science Foundation of University of Jinan under Grant No. XKY1310.

\section{References}

[1] F. Sun, Consumer Behavior Quantitative Research, ShangHai, CN: Shanghai People's Publishing House, 2002.
[2] F.D. Qiu and M.Z. Wu, "A Research on Tourism Decision-Making and its Influencing Factors," Psychological Science, vol. 27, no. 5, pp. 1214-1217, September 2004.

[3] J.L. Qin and L. Lin, "The Effect Mechanism Comparison on Tourism Decision-Making in Both Genders Based on AMOS Technique - A Case Study of Fuzhou Residents," Economic Geography, vol. 34, no. 4, pp. 186-192, April 2014.

[4] H. Luo, X. Chen and Z.W. He, "Empirical Study on Rural-tourism Decision-making Behavior in the Perspective of Low-carbon: Based on the Survey of 300 Tourists in Beijing," Chinese Agricultural Science Bulletin, vol. 30, no. 34, pp.294-302, December 2014.

[5] F.D. Qiu and J. Wang, "A Survey on Tourism Decision making Process," Tourism Science, vol. 19, no. 02, pp.1-5, March 2005.

[6] Y. Wang and Z.F. Huang, "An Analysis on Domestic Tourists' Consumption Structure and the Related Factors of Behavior - Taking Nanjing City As an Example," Journal of Nanjing Normal University(Natural Science Edition), vol. 28, no.04, pp.123-126, October 2005

[7] H. Zhang, Z.D. Cheng and X.F. Wang, "Analysis of Factors Impacting on Domestic Tourism Demand among Urban Residents and Countermeasures Research," Resource Development \& Market, vol. 30, no. 6, pp.763-768, June 2014.

[8] G.Q. Huang, Y. Zhao and D.H. Qi, "Demonstrative Research on Tourist Behavior of Chong Qing Citizens," Journal of Sichuan Teachers College (Social Science), vol. 24, no. 06, pp. 12-15, December 2003.

[9] J.Zhou and W. Jin, "Analyses the protection and management of scenic spot - Taking daming lake scenic area as an example," Landscape Science and Technology, vol. 32, no. 1, pp. 44-46, January 2013.

[10] K.Bai and G.Q Fu, "Perspective of the Theory of Localization in the Study of Family Travel Decision-making and Train of Thoughts for Analysis," Tourism Tribune, vol. 26, no. 11, pp. 49-56, December 2011.

[11] Horna J. "The leisure component of the parental role," Journal of Leisu re Research, vol. 21, no. 2, pp. 28-241, December 1989. 